\title{
Changes in Performance on the Balance Board Test and Motor Fitness over Time in Elderly Women
}

\author{
Hiroki Sugiura ${ }^{1, *}$, Shunsuke Yamaji ${ }^{2}$, Takayoshi Yamada ${ }^{3}$, Shigeru Shimada $^{1}$, \\ Takanori Noguchi ${ }^{1}$, Tomohisa Yokoya ${ }^{1}$ \\ ${ }^{1}$ Faculty of Sports and Health Sciences, Fukui University of Technology, Fukui, Japan \\ ${ }^{2}$ Faculty of Medical Sciences, University of Fukui, Fukui, Japan \\ ${ }^{3}$ Faculty of Education, Humanities and Social Sciences, University of Fukui, Fukui, Japan \\ *Corresponding author: sugiura@fukui-ut.ac.jp
}

Received November 17, 2018; Revised January 09, 2019; Accepted January 21, 2019

\begin{abstract}
The balance board (BB) test is used to assess balance ability, but, with age, individuals become unable to successfully perform the test. Our objective was to investigate the changes in performance on the BB test and motor fitness over time in elderly women. A total of 52 elderly women who were able to stand on both legs on a rocking unstable board for $20 \mathrm{~s}$ were enrolled. Subjects were classified into two groups according to their ability to perform the task 1 year later [able group (A); $n=35$ ] or not [unable group (U); $n=17$ ]. The results of our analysis indicated that the height of women in the U group had decreased over the 1-year period. At both time points, the women in the U group had worse one-leg standing and walking times than those in the A group. Our findings indicate that inferior motor fitness in the pre-stage and reduced height after 1 year are factors that contribute to the poor performance of elderly people on the BB test.
\end{abstract}

Keywords: annual change, dynamic balance ability, unstable board

Cite This Article: Hiroki Sugiura, Shunsuke Yamaji, Takayoshi Yamada, Shigeru Shimada, Takanori Noguchi, and Tomohisa Yokoya, "Changes in Performance on the Balance Board Test and Motor Fitness over Time in Elderly Women." Journal of Physical Activity Research, vol. 4, no. 1 (2019): 47-50. doi: 10.12691/jpar-4-1-5.

\section{Introduction}

Aging is accompanied by marked decrease in physical functions, which is associated with an increased need for nursing care. However, the effect of age-related problems can be reduced or controlled by maintaining and increasing physical functions. Therefore, it is important to regularly ascertain the physical functions of elderly people in the community in order to detect the changes in these abilities and examine methods of intervention.

Previously, simple tests conducted at any location were selected to assess the physical functions of elderly people. One example of such a test is the "Physical fitness test by the Ministry of Education, Culture, Sports, Science and Technology of Japan." This test assesses the isometric grip strength (muscle function), open-eyed one-leg standing (neurological function), anteflexion in a straight-legged position (joint function), and 6-minute walking. In addition, a test including typical activities of daily living (ADL) can be represented by the 10-meter walk test (10-MWT) with obstacles, the timed up-and-go test, and the cross-step moving on four spots test [1]. Many of these tests assess the physical fitness and motor fitness individually based on the measured values. However, most people are able to perform these tasks, and owing to the low level of difficulty of these tasks, even for elderly people who require nursing care, these tests may not provide an adequate assessment of physical functions.

The balance board (BB) test is designed to assess the ability of elderly people to maintain position on an unstable board and utilizes unpredictable stimuli [2,3]. It has been used to assess the physical functions and risk of falling in active elderly people. Because this test involves a board that is not fixed in place (an unstable board) and the board's position changes with the subject's balance, the subject must have sufficient balance to maintain position under unstable conditions in order to successfully perform the test. Owing to the high level of difficulty of this task, some elderly people are unable to perform the test. Sugiura et al [3] reported that elderly people unable to perform the BB test have had more falls and have a decreased balance and walking abilities and ADL in comparison to elderly people who are able to complete the tasks of the BB test. A longitudinal investigation is required to identify the reason why some individuals are unable to perform the task [4]. Longitudinal studies of changes in the motor fitness and cognitive function associated with interventions include studies by Liu-Ambrose et al [5] and Muscari et al [6], conducted for approximately 1 year, and studies by Tsutsumi et al [7] and Maki et al [8], conducted for approximately 3 months. As such, the intervention duration of the studies differ; however, because elderly 
people experience an annual decline in physical functions of approximately $1 \%[9,10]$, it is important to investigate the changes occurring over the span of 1 year.

The objective of our study was to conduct a longitudinal investigation of the performance on the BB test and the motor fitness in elderly people.

\section{Methods}

\subsection{Subjects}

We enrolled 52 elderly women who were able to independently engage in daily activities and participated once every week or every other week in health classes or social education programs held by their local municipality. They underwent measurements for 2 continuous years (2015 and 2016 or 2016 and 2017) in either August or September. After detailed explanations of the purpose and procedures of this study, all subjects willingly signed informed consent. The Ethics Committee on Human Experimentation of Fukui University of Technology approved the experimental protocol (Ref. No. 2015-1).

\subsection{Balance Board Test (BB test)}

In BB test, we used the DYJOC Board (SAKAI Medical, Japan). This device comprises a flat board with two dome-shaped hubs attached to its underside. The board tilts a maximum of 17 degrees to the right and left. The sensor attached to the board detects tilts in all directions during testing, and the measured values thus obtained are recorded on a computer using the device's data log. Using previous studies as references, the subjects were instructed to perform two-leg standing periods of 20 $\mathrm{s}$ on the unstable board that was rocked only to the left and right. They performed this task twice with a 1-min rest period between the two attempts. The attempts were considered failures if the edges of the board contacted the floor during testing or if either of the subject's feet contacted the ground. The 52 subjects who succeeded at this task on both attempts were classified according to their ability to succeed again 1 year later into the able group [(A); $\mathrm{n}=35]$ and unable group [(U); $\mathrm{n}=17]$.

We also assessed the following variables: stability index (angle changes of the board during testing, using the horizontal as the standard line), range of angular fluctuation (the range within which the angle of the board fluctuated during testing, using the mean angle of incline as the standard), and total angular fluctuation index (the total board angle degree change during testing). In all cases, we interpreted higher values to be indicative of lower balance ability and vice versa. We also selected representative values from the second attempt.

\subsection{Physical Characteristics and Motor Fitness}

We assessed the physical characteristics by measuring height, body weight, and bone strength [using an ultrasonic bone densitometer (Hitachi Aloka Medica, Japan)]. The assessments of leg muscle strength were performed by measuring hip flexion and knee extension strengths. Each of these was conducted using a $\mu$ TAS (Anima, Japan) and a tension meter attachment (Takei Scientific Instruments, Japan). We measured the right and left sides once and used the mean values for each as the representative values. The assessments of balance ability were performed using open-eyed one-leg standing times and functional reach (FR). We used open-eyed one-leg standing to measure the time (max: $120 \mathrm{~s}$ ) during which the subjects were able to maintain the standing position on either the left or right leg. When performing the FR test, the subjects used an elastic stick, as in the study conducted by Demura and Yamada [11]. We asked subjects to perform each of the above tests once. We assessed multiple motor fitness using the 10-MWT (with obstacles).

\subsection{Statistical Analysis}

The chronological changes and intergroup differences for all variables were analyzed using a two-way ANOVA (time $\times$ group). When significant interactions or mean effect was found, post-hoc comparisons were performed using the Tukey Honest significant difference test. The intergroup differences in variables related to the pre-stage $\mathrm{BB}$ test were analyzed using the unpaired t-test. In addition, chronological changes in variables related to the BB test in the A group were analyzed using the paired ttest. The effect size ( $\eta^{2}$ or $\left.d\right)$ was calculated in order to investigate the size of the difference in mean values. We based our hypothesis testing on the significance standard set at $5 \%$.

\section{Results}

Table 1 shows the statistical values for age, height, body weight, and bone density according to time point and group, and the differences between their means based on the test results. Only with respect to height, a significant difference was found between groups; subjects in group $\mathrm{U}$ had lower heights after 1 year than initially. The main effect in the time point factor was observed for age and weight. Age was higher after 1 year, but weight was higher initially. The effect size was large for time and interaction factors $\left(\eta^{2}=0.17-0.80\right)$.

Table 2 shows the baseline statistical values for all variables related to the $\mathrm{BB}$ test in both groups, and the differences between their means based on the test results. We found significant differences for all variables, with subjects in group A having higher values than those in group U. The effect size was moderate or larger $(\mathrm{d}=0.60-1.03)$.

Table 3 shows the statistical values for all variables related to the BB test at both time points for subjects in group A, and differences between their means based on the test results. We found no significant differences in any of the variables examined.

Table 4 shows the statistical values for motor fitness according to time point and group, and the differences between their means based on the test results. We found no significant interactions for any of the variables. The main effect in the group factor was observed for one-leg standing and 10-meter walking times; at both time points, subjects in group $\mathrm{U}$ had lower values than those in group A. The effect size was moderate or larger $\left(\eta^{2}=0.08,0.10\right)$. 
Table 1. Statistical values for age, height, body weight, and bone density according to time point and group

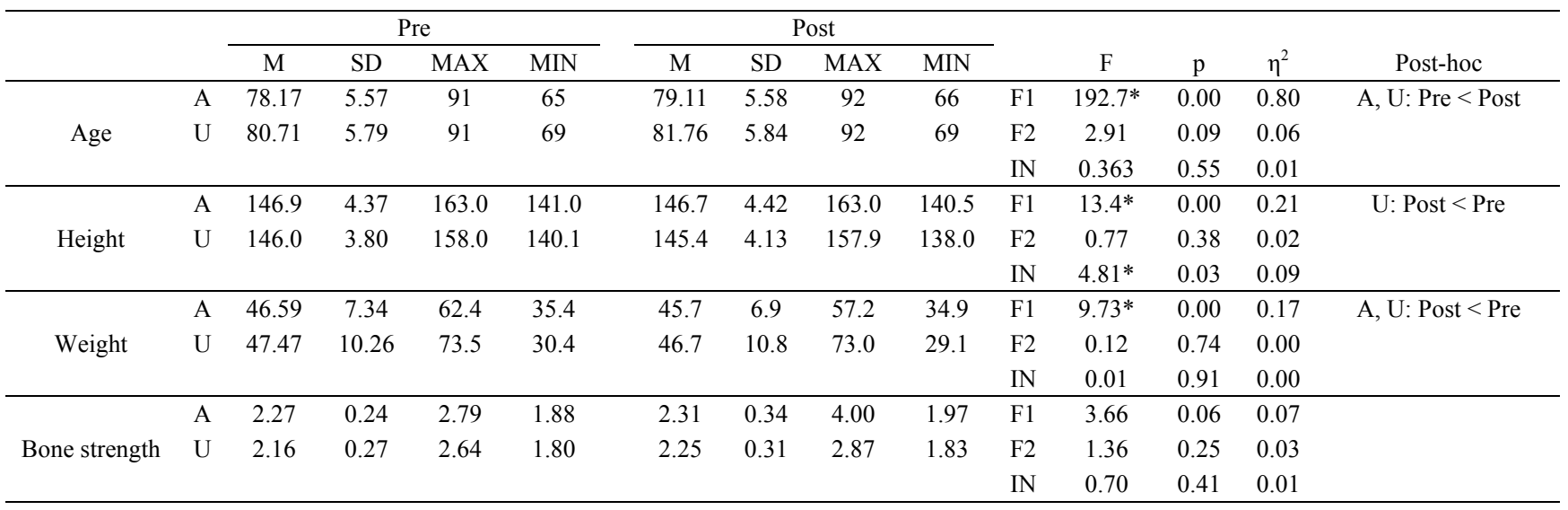

Note) F1: Time point, F2: Group, F3: Interaction, A: Group A, U: Group U. *:p $<0.05$.

Table 2. Baseline statistical values for all variables related to the BB test in both groups

\begin{tabular}{|c|c|c|c|c|c|c|c|c|c|c|c|}
\hline & \multicolumn{4}{|c|}{ Group A } & \multicolumn{4}{|c|}{ Group U } & \multirow[b]{2}{*}{$\mathrm{t}$} & \multirow[b]{2}{*}{$\mathrm{p}$} & \multirow[b]{2}{*}{$\mathrm{d}$} \\
\hline & M & SD & MAX & MIN & $\mathrm{M}$ & SD & MAX & MIN & & & \\
\hline Stability index & 4.38 & 1.59 & 7.66 & 1.27 & 6.82 & 2.66 & 12.30 & 3.15 & $3.74^{*}$ & 0.00 & 1.03 \\
\hline Angular fluctuation range & 2.68 & 1.02 & 6.18 & 1.00 & 4.69 & 2.00 & 9.43 & 2.07 & $4.18^{*}$ & 0.00 & 1.15 \\
\hline Total angular fluctuation index & 518.3 & 308.0 & 1587.5 & 139.7 & 735.6 & 419.8 & 2095.0 & 273.9 & $2.18^{*}$ & 0.03 & 0.60 \\
\hline
\end{tabular}

Note) $*$ p $<0.05$.

Table 3. Statistical values for all variables related to the BB test at both time points for subjects in group A

\begin{tabular}{|c|c|c|c|c|c|c|c|c|c|c|}
\hline & \multicolumn{4}{|c|}{ Pre } & \multicolumn{4}{|c|}{ Post } & \multirow[b]{2}{*}{$\mathrm{t}$} & \multirow[b]{2}{*}{$\mathrm{p}$} \\
\hline & $\mathrm{M}$ & SD & MAX & MIN & $\mathrm{M}$ & SD & MAX & MIN & & \\
\hline Stability index & 4.38 & 1.59 & 7.66 & 1.27 & 4.05 & 2.00 & 11.49 & 0.52 & 1.14 & 0.26 \\
\hline Angular fluctuation range & 2.68 & 1.02 & 6.18 & 1.00 & 2.68 & 1.55 & 8.90 & 0.40 & 0.01 & 0.99 \\
\hline Total angular fluctuation index & 518.3 & 308.0 & 1587.5 & 139.7 & 507.1 & 350.0 & 1884.5 & 132.2 & 0.38 & 0.71 \\
\hline
\end{tabular}

Table 4. Statistical values for motor fitness according to time point and group

\begin{tabular}{|c|c|c|c|c|c|c|c|c|c|c|c|c|c|c|}
\hline & & \multicolumn{4}{|c|}{ Pre } & \multicolumn{4}{|c|}{ Post } & & \multirow[b]{2}{*}{$\mathrm{F}$} & \multirow[b]{2}{*}{$\mathrm{p}$} & \multirow[b]{2}{*}{$\eta^{2}$} & \multirow[b]{2}{*}{ Post-hoc } \\
\hline & & $\mathrm{M}$ & SD & MAX & MIN & $\mathrm{M}$ & SD & MAX & MIN & & & & & \\
\hline \multirow{3}{*}{$\begin{array}{l}\text { Hip flexion } \\
\text { strength }\end{array}$} & $\mathrm{A}$ & 13.02 & 3.22 & 23.1 & 8.7 & 12.71 & 4.03 & 24.2 & 6 & F1 & 2.30 & 0.14 & 0.05 & \\
\hline & $\mathrm{U}$ & 13.01 & 4.13 & 21.4 & 7.4 & 11.55 & 3.19 & 19.2 & 4.6 & F2 & 0.28 & 0.60 & 0.01 & \\
\hline & & & & & & & & & & IN & 0.76 & 0.39 & 0.02 & \\
\hline \multirow{3}{*}{$\begin{array}{l}\text { Knee extension } \\
\text { strength }\end{array}$} & $\mathrm{A}$ & 8.85 & 2.24 & 13.42 & 4.43 & 8.49 & 2.75 & 18.26 & 4.63 & F1 & 0.74 & 0.40 & 0.02 & \\
\hline & $\mathrm{U}$ & 8.13 & 2.62 & 12.28 & 3.46 & 7.74 & 2.35 & 12.92 & 3.21 & F2 & 1.08 & 0.30 & 0.02 & \\
\hline & & & & & & & & & & IN & 0.00 & 0.97 & 0.00 & \\
\hline \multirow{3}{*}{ One leg standing } & $\mathrm{A}$ & 50.84 & 37.76 & 120 & 4.2 & 53.02 & 42.22 & 120 & 6.3 & F1 & 0.76 & 0.39 & 0.02 & Pre, Post: $\mathrm{U}<\mathrm{A}$ \\
\hline & U & 35.69 & 37.36 & 120 & 4.4 & 25.04 & 27.21 & 109.27 & 1.23 & $\mathrm{~F} 2$ & $4.46^{*}$ & 0.04 & 0.08 & \\
\hline & & & & & & & & & & IN & 1.50 & 0.23 & 0.03 & \\
\hline \multirow{3}{*}{ Functional reach } & $\mathrm{A}$ & 33.07 & 6.55 & 52.5 & 22.5 & 31.66 & 6.89 & 50 & 16.8 & F1 & 0.18 & 0.68 & 0.00 & \\
\hline & U & 29.09 & 5.16 & 39.1 & 17 & 31.08 & 6.38 & 40.9 & 16 & F2 & 1.76 & 0.19 & 0.04 & \\
\hline & & & & & & & & & & IN & 2.24 & 0.14 & 0.04 & \\
\hline \multirow{3}{*}{ Waking time } & A & 5.67 & 0.91 & 7.91 & 4.18 & 5.72 & 1.20 & 8.65 & 3.73 & F1 & 1.73 & 0.20 & 0.03 & Pre, Post: $\mathrm{A}<\mathrm{U}$ \\
\hline & $\mathrm{U}$ & 6.33 & 1.31 & 9.00 & 4.24 & 6.70 & 1.79 & 10.98 & 4.48 & $\mathrm{~F} 2$ & $5.24 *$ & 0.03 & 0.10 & \\
\hline & & & & & & & & & & IN & 1.28 & 0.19 & 0.04 & \\
\hline
\end{tabular}

Note) F1: Time point, F2: Group, F3: Interaction, A: Group A, U: Group U. *:p $<0.05$.

\section{Discussion}

Aging is accompanied by a decrease in physical fitness and motor fitness, and statistical analyses can produce comparison standards to assess individual physical characteristics such as height, weight, and bone density. If the measured values are lower than the standard, the affected individual will tend to display low physical fitness and motor fitness. Thus, when conducting research on elderly people, age and physical characteristics must be considered. Our results indicated a lack of significant intergroup differences in any of the aforementioned variables at either time point, and we were able to interpret the groups as being composed of similar populations.

In general, physical function and motor fitness both contribute to performance. In the present study, performance on the $\mathrm{BB}$ test initially was worse in the $\mathrm{U}$ group than in the A group. In addition, the motor fitness as measured by one-leg standing and 10-MWT was worse in the $U$ group than in the A group at both time points. The BB test examines dynamic balance ability [12]. Dynamic balance is also examined during walking tests because 
people move their support base in conjunction with their balance when walking [13]. During walking tests, individuals move their body voluntarily; however, during the BB test, involuntary responses are made to unexpected stimuli. Although different balance abilities are involved in each case, our results suggest that some balance abilities are at play to some extent in both cases.

During the older years, sarcopenia causes muscle atrophy. This in turn leads to an associated decline in body weight. The women in both groups in our study showed decreased body weight after 1 year. Despite the fact that they attended health classes approximately once per week, they did not receive professional training guidance and each subject practiced regular walking and simple muscle strength training on their own. As a result, they were able to maintain their leg strength but experienced systemic muscle atrophy, which led to decreased body weight. Thus, it remains necessary to investigate trunk muscle mass and changes in muscle strength. On the other hand, a decrease in height was noted only among women in the U group. Causes of reduced height in the elderly include atrophy of the intervertebral discs in the spine, anteflexion of the posture, and osteoporosis [14]. In our study, we did not observe significant chronological changes or intergroup differences in bone density. The elderly women who were unable to perform the BB test after 1 year showed changes in their posture during the intervening year as well as changes in the strategies for maintaining their position. These factors may have been the cause of their difficulty in succeeding at the BB test. In addition, $29.4 \%$ of elderly women in the $\mathrm{U}$ group had articular disorder (ankle, knee, and/or hip joints) during follow-up. Future studies are required to focus on the issue of changes in posture and joint function.

Due to the fact that the subjects in the present study practiced regular physical activities, their motor fitness showed no chronological changes in either group. However, although women in the A group showed no changes in their performance on the BB test, those in the $\mathrm{U}$ group were unable to perform the BB test after 1 year. In addition, women in the $U$ group showed decreased motor fitness than those in the A group during multiple exercises from the beginning. This suggests that even when motor fitness is maintained, in individuals with poor motor fitness for tasks that require balance to begin with, weakening muscles and neural functions that accompany aging can contribute to the inability to perform the BB test after 1 year. The results of performance tests with high levels of difficulty, such as those conducted in our study, performed in conjunction with conventional physical fitness tests can provide an accurate assessment of the degree to which the elderly women have become weaker.

In conclusion, the factors affecting the ability of elderly women to perform the BB test after 1 year included the initial performance on the test, a decreased motor fitness for tasks that require balance ability, and reduced height.

\section{Acknowledgements}

This work was supported by JSPS KAKENHI Grant Number JP16K21451.

\section{Conflict of interest statement}

The authors declare no conflicts of interest associated with this manuscript.

\section{References}

[1] Yamaji, S., and Demura, S. "Reliability and fall experience discrimination of cross step moving on four spots test in the elderly," Archives of Physical Medicine Rehabilitation, 94(7). 1312-1319. 2013.

[2] Ogaya, S., Ikezoe, T., Soda, N., and Ichihashi, N. "Effects of balance training using wobble boards in the elderly," The Journal of Strength and Conditioning Research. 25(9). 2616-2622. 2011.

[3] Sugiura, H., Demura, S., and Uchida, Y. "Effect of achievement possibility of a balance board test on physical functions, ADL, fall experience, and fall risk in elderly females," American Journal of Sports Science and Medicine, 4(1). 1-5. 2016.

[4] Suzuki, T., Sugiura, M., Furuna, T., Nishizawa, S., Yoshida, H., Ishizaki, T., Kim, H., Yukawa, H. and Shibata H. "Association of physical performance and falls among the community elderly in Japan in a five year follow-up study," Japanese Journal of Geriatrics, 36(7). 472-478. 1999.

[5] Liu-Ambrose, T., Nagamatsu, L.S., Graf, P., Beattie, B.L., Ashe, M.C., and Handy, T.C. "Resistance training and executive functions: a 12-month randomized controlled trial," Archives Internal Medicine, 170(2). 170-178. 2010.

[6] Muscari, A., Giannoni, C., Pierpaoli, L., Berzigotti, A., Maietta, P., Foschi, E., Ravaioli, C., Poggiopollini, G., Bianchi, G., Magalotti, D., Tentoni, C., and Zoli, M. "Chronic endurance exercise training prevents aging-related cognitive decline in healthy older adults: a randomized controlled trial," International Journal of Geriatric Psychiatry, 25(10). 1055-1064. 2010.

[7] Tsutsumi, T., Don, B.M., Zaichkowsky, L.D., and Delizonna, L.L. "Physical fitness and psychological benefits of strength training in community dwelling older adults," Applied Human Science, 16(6). 257-266. 1997

[8] Maki, Y., Ura, C., Yamaguchi, T., Murai, T., Isahai, M., Kaiho, A., Yamagami, T., Tanaka, S., Miyamae, F., Sugiyama, M., Awata, S., Takahashi, R., and Yamaguchi, H. "Effects of intervention using a community-based walking program for prevention of mental decline: a randomized controlled trial," Journal of the American Geriatrics Society, 60(3). 505-510. 2012.

[9] Frontera, W.R., Hughes, V.A., Lutz, K.J., and Evans, W.J. "A cross-sectional study of muscle strength and mass in 45- to 78-yrold men and women," Journal of Applied Physiology, 71(2). 644650. 1991.

[10] Kuzuya, M. "Impact of sarcopenia and frailty on elderly health," Japanese Journal of Geriatrics, 46(4). 279-285. 2009.

[11] Demura, S., and Yamada, T. "Simple and easy assessment of falling risk in the elderly by functional reach test using elastic stick," The Tohoku Journal of Experimental Medicine, 213(2). 105-111. 2007.

[12] Sugiura, H., and Demura, S. "The relationship between stepping test, functional reach test, and balance board test in healthy male students," Advances in Research, 3(6). 571-576. 2015.

[13] Takeshima, N., and Rogers, M.E. Theory and practice of the balance exercise for the fall prevention, Nap, Tokyo, 2010, 11-18.

[14] Demura, S. Fall prevention for the elderly, Kyorin shoin, Tokyo, 2012, 69 . 